\title{
Factors in genetic susceptibility in a chemical sensitive population using QEESI
}

\author{
Saeko Fujimori $\cdot$ Mizue Hiura $\cdot$ Cui Xiao Yi • \\ Lu Xi · Takahiko Katoh
}

Received: 17 October 2011/Accepted: 5 December 2011/Published online: 29 December 2011

(C) The Japanese Society for Hygiene 2011

\begin{abstract}
Objectives Inherited impairment of xenobiotic metabolism is a postulated mechanism underlying environmentally associated pathogeneses such as multiple chemical sensitivity (MCS). Using the Quick Environmental Exposure and Sensitivity Inventory (QEESI), we defined people who have a strong response to chemical substances as "chemical sensitive populations (CSP)." The aim of this study is to evaluate the condition of subjects sensitive to chemicals and to analyze their genotypes in order to identify susceptibility factors in CSPs in Japanese populations.

Methods A total of 1,084 employees of Japanese companies were surveyed using the QEESI, history of MCS, and sick house syndrome. The common genotypes of the participants were analyzed for glutathione S-transferase (GST) M1, GSTT1, aldehyde dehydrogenase2 (ALDH2), and paraoxonasel (PONI) in order to identify factors in the susceptibility to sensitivity to chemicals.

Results Four subjects had history of diagnosis of MCS; no subjects had diagnosis of sick house syndrome. The subjects were divided into four levels according to scores of $0,1-19,20-39$, and 40 or more on three of the QEESI subscales. In addition, we used the MCS criteria by Hojo to differentiate between cases (CSP) and controls. No significant differences in the allelic distribution of genetic polymorphisms in the GSTM1, GSTT1, ALDH2 or PON1
\end{abstract}

Electronic supplementary material The online version of this article (doi:10.1007/s12199-011-0260-8) contains supplementary material, which is available to authorized users.

S. Fujimori · M. Hiura · C. X. Yi · L. Xi · T. Katoh $(\bowtie)$ Department of Public Health, Faculty of Life Sciences, Kumamoto University, 1-1-1 Honjou,

Kumamoto 860-8556, Japan

e-mail: katoht@gpo.kumamoto-u.ac.jp genes were found among the four levels of each subscale, or between cases and controls.

Conclusions Our findings suggest that the common genotypes of GSTM1, GSTT1, ALDH2, and PON1 are of little importance to CSP in a Japanese population.

Keywords Genetic susceptibility - Multiple chemical sensitivity (MCS) - Idiopathic environmental intolerance (IEI) - Quick Environmental Exposure and Sensitivity Inventory (QEESI) · Logistic regression analysis

\section{Introduction}

Multiple chemical sensitivity (MCS), also known as idiopathic environmental intolerance [1], has been described as disabling multi-organ symptoms triggered by multiple exposures to chemicals. A number of hypotheses concerning the etiology and pathophysiology of MCS have been proposed [2], including impaired ability to metabolize toxic chemicals [3] and psychological mechanisms [4].

There is no widely accepted instrument to measure general chemical intolerance, and no objective criteria for identification of chemicals contributing to MCS, but Miller and Prihoda [5, 6] developed the Quick Environmental Exposure and Sensitivity Inventory (QEESI), which has its origins in the Environment Exposure and Sensitivity Inventory [7]. The QEESI is a reliable and valid screening instrument for chemical intolerance that consists of five subscales: chemical sensitivity, other chemical sensitivity, symptom severity, life impact, and masking index. The Japanese version of the QEESI was translated by Ishikawa and Miyata in 1999 [8].

The present study was designed to determine whether the results of the QEESI reveal a genetic difference for 
specific enzymes, primarily those possibly associated with chemical detoxification: glutathione $S$-transferase (GST) M1, GSTT1, aldehyde dehydrogenase 2 (ALDH2), and paraoxonase 1 (PON1).

The GSTs are a family of multifunctional enzymes and play a central role in detoxification of toxic and carcinogenic electrophiles. The polymorphic GSTs catalyze conjugation of glutathione to a variety of electrophilic compounds, including formaldehyde. Absence of activity of GSTM1, a $\mu$ class enzyme which detoxifies the reactive metabolites of benzo $[a]$ pyrene and other polycyclic aromatic hydrocarbons, is due to homozygous deletion of the gene [9]. A similar polymorphism of the GSTT1 gene, encoding the $\theta$ class enzymes, has been described [10]. GSTT1 metabolizes various potential carcinogens, such as monohalomethanes, which are widely used as methylating agents, pesticides, and solvents [9].

Although GSTs are presumed to be involved in the first step of formaldehyde metabolism, it is still not clear which GST molecular species is responsible for formaldehyde metabolism. In addition, GST cytosolic activity in olfactory epithelium, the highest among extrahepatic tissues [11], is of particular interest in MCS, where the role of odorous triggers is important.

Acetaldehyde is one of the important chemicals that induce sick house syndrome and MCS [12]. Approximately half of the Japanese population lack ALDH2 activity because of a structural point mutation in the $A L D H 2$ gene. This genetic polymorphism, which is seen in Asians, including Japanese, but not in Caucasians, results in catalytic deficiency of aldehyde metabolism [13]. However, there are few studies regarding MCS and genetic polymorphism among Asians.

PON1 is known to be polymorphic in humans, with two isoforms displaying distinct hydrolyzing activities. The Arg192 isoform hydrolyzes paraoxon rapidly, whereas the Gln192 isoform acts slowly [14]. PON1 genes were associated with Gulf War Syndrome [15], and PON1 reacts with toxic organophosphorus compounds [16].

\section{Methods}

\section{Subjects}

The present study was conducted from August to October 2003 at two companies (company A, an integrated circuit manufacturing company; company $\mathrm{B}$, a paper pulp producing company) in Kyushu, in the south of Japan. The participants numbered 1,310 people from company A (males 936, females 374) and 891 from company B (males 778 , females 113). Those who replied to the questionnaires $(90.2 \%)$ and furthermore agreed to give genetic samples
(52.2\%) were included. Finally, a total of 1,084 subjects (49.3\%) who had purified DNA in good condition, including 502 subjects from company A (males 390, females 112) and 582 from company B (males 579, females 3 ), were eligible for this study (Table 1).

Table 1 Demographic characteristics of the subjects

\begin{tabular}{|c|c|}
\hline & All subjects \\
\hline \multicolumn{2}{|l|}{ Sex } \\
\hline Male & $969(89.4 \%)$ \\
\hline Female & $115(10.6 \%)$ \\
\hline Total & 1,084 \\
\hline \multicolumn{2}{|c|}{ Average age (range), years } \\
\hline Male & $42.2 \pm 8.9(19-63)$ \\
\hline Female & $32.3 \pm 6.3(23-67)$ \\
\hline Total & $41.2 \pm 9.1(19-67)$ \\
\hline \multicolumn{2}{|c|}{ Smoking (>once/week) } \\
\hline Male & $572(59.0 \%)$ \\
\hline Female & $31(27.0 \%)$ \\
\hline Total & $603(55.6 \%)$ \\
\hline \multicolumn{2}{|c|}{ Drinking (>once/week) } \\
\hline Male & $742(76.6 \%)$ \\
\hline Female & $43(37.4 \%)$ \\
\hline Total & $785(72.4 \%)$ \\
\hline \multicolumn{2}{|c|}{ History of diagnosis } \\
\hline \multicolumn{2}{|c|}{ Multiple chemical sensitivity } \\
\hline Male & $2(0.2 \%)$ \\
\hline Female & $2(0.2 \%)$ \\
\hline Total & $4^{\mathrm{a}}(0.3 \%)$ \\
\hline \multicolumn{2}{|c|}{ Sick house syndrome } \\
\hline Male & $0(0 \%)$ \\
\hline Female & $0(0 \%)$ \\
\hline Total & $0(0 \%)$ \\
\hline \multicolumn{2}{|c|}{ Allergic disease } \\
\hline Male & $212(21.9 \%)$ \\
\hline Female & $47(40.9 \%)$ \\
\hline Total & $259^{\mathrm{a}}(23.9 \%)$ \\
\hline \multicolumn{2}{|c|}{ Chemical sensitivity $\geq 40$} \\
\hline Male & $60(6.2 \%)$ \\
\hline Female & $8(7.0 \%)$ \\
\hline Total & $77(7.1 \%)$ \\
\hline \multicolumn{2}{|c|}{ Other chemical sensitivity $\geq 25$} \\
\hline Male & $29(3.0 \%)$ \\
\hline Female & $5(4.3 \%)$ \\
\hline Total & $34(3.1 \%)$ \\
\hline \multicolumn{2}{|c|}{ Symptom severity $\geq 40$} \\
\hline Male & $68(7.0 \%)$ \\
\hline Female & $6(5.2 \%)$ \\
\hline Total & $74(6.8 \%)$ \\
\hline
\end{tabular}

\footnotetext{
${ }^{a}$ Three subjects had both multiple chemical sensitivity and allergy disease
} 


\section{Instruments}

We used the QEESI (Japanese version) [8] for the survey described above. The QEESI consists of five subscales: the chemical sensitivity subscale measures the extent to which certain odors or exposures make one sick, the other chemical sensitivity subscale measures the extent to which a variety of other exposures make one sick, the symptom severity subscale refers to the extent to which one experiences certain symptoms, the life impact subscale measures the extent to which the sensitivity affects certain aspects of life, and the masking index measures whether there are ongoing exposures from routinely used products. Unlike other studies in which the subjects were patients, the participants in our study were collected from the general population. We selected 3 of the subscales, eliminating life impact and masking index. Each subscale has ten questions, and each question has a possible score of $0-10$. Therefore, the total possible score was 0-100. All study subjects completed a selfreporting questionnaire which covered history of MCS, sick house syndrome, and allergic disease, drinking history, and smoking history.

As defined by Miller and Prihoda [5, 6], scores on the QEESI reveal three levels of symptom: low, medium, and high. The criteria for chemical sensitivity and symptom severity are low $=0-19$, medium $=20-39$, and high $=$ 40-100. The criteria for other chemical sensitivity are low $=0-11$, medium $=12-24$, and high $=25-100$. It has been reported that these three subscales can distinguish individuals with high susceptibility and a control group using cutoff values [5].

Hojo et al. [17] designed a study to establish a new cutoff value for Japanese using the QEESI for screening of MCS patients. According to that study, one difference from patients in America was that in Japanese patients the other chemical sensitivity subscale had low sensitivity and low specificity. They concluded that the other chemical sensitivity subscale should be excluded when applying the QEESI to evaluate subjective symptoms in Japan. The new cutoff values for Japanese subjects were determined to be $\geq 40$ for the chemical sensitivity subscale, $\geq 20$ for the symptom severity subscale, and $\geq 10$ for the life impact subscale. Using their criteria, we divided our subjects into two groups according to the score achieved (Table 2). Individuals with chemical sensitivity score $\geq 40$ and symptom severity score $\geq 20$ were defined as chemical sensitive population (CSP) (cases), while individuals with moderate or no symptoms were classified as nonsensitive (controls, chemical sensitivity score $<39$ or symptom severity score $<19$ ).
Table 2 Demographic characteristics of cases and controls defined by QEESI score

\begin{tabular}{llll}
\hline & $\begin{array}{l}\text { Cases }(\mathrm{CSP})^{\mathrm{a}} \\
(n=47)\end{array}$ & $\begin{array}{l}\text { Controls } \\
(n=1,037)\end{array}$ & $P$ value \\
\hline $\begin{array}{l}\text { Sex } \\
\quad \text { Male }\end{array}$ & $41(87.2 \%)$ & $928(89.5 \%)$ & \\
$\quad$ Female & $6(12.8 \%)$ & $109(10.5 \%)$ & $0.62^{\mathrm{b}}$ \\
$\begin{array}{l}\text { Average age, years } \\
\text { Mean } \pm \text { SD }\end{array}$ & $44.2 \pm 8.8$ & $41.1 \pm 9.1$ & $0.69^{\mathrm{c}}$ \\
$\begin{array}{l}\text { Median (range) } \\
\begin{array}{l}\text { Smoking status } \\
(>\text { once/week) }\end{array}\end{array}$ & $44(30-59)$ & $41(19-67)$ & \\
$\begin{array}{l}\text { Drinking status } \\
(>\text { once/week) }\end{array}$ & $32(38.3 \%)$ & $585(56.4 \%)$ & $0.01^{\mathrm{b}}$ \\
\hline
\end{tabular}

Cases (chemical sensitive population, CSP): chemical sensitivity score $\geq 40$ and symptom severity score $\geq 20$. Controls: chemical sensitivity score $\leq 39$ or symptom severity score $\leq 19$

a Classification in cases and controls according to Hojo et al. [17]

b $P$ value, chi-square test. $P<0.05$, difference significant

c $P$ value, Student's $t$-test. $P<0.05$, difference significant

\section{Genotyping}

Genomic DNA was isolated from peripheral leukocytes by proteinase $\mathrm{K}$ digestion, phenol/chloroform extraction, and ethanol precipitation. A multiplex polymerase chain reaction (PCR) method was used to detect the presence or absence of GSTMIand GSTT1 [18].

Absence of GSTM1 and GSTT1 is due to homozygous deletion of these hereditary genes, termed the null genotype. The genotypes of $A L D H 2$ (rs671) were identified by the method of Harada and Zhang [13] as the homozygous genotype of normal ALDH2 (*1/*1), the homozygous genotype of inactive $A L D H 2(* 2 / * 2)$, and the heterozygous genotype of normal and inactive ALDH2 (*1/*2). The genotype of the Gln192Arg (rs662) polymorphism of the PON1 gene was determined essentially as described previously [19].

\section{Statistical analysis}

Relative associations between the CSP and controls were assessed by calculating crude odds ratios (ORs) from contingency tables. Corresponding chi-square tests were carried out on the cases and controls. In logistic regression analysis, ORs with corresponding $95 \%$ confidence intervals (CI) were calculated. $P$ values smaller than 0.05 were considered significant. Statistical analysis was carried out using SPSS version 19. 
Statistical power calculations were performed using Epistat (Finnish Institute of Occupational Health). This study sample size had at least $80 \%$ power (two-sided test significant, $\alpha$ of 0.05 ) to detect an OR of at least 2.5 , following the calculations used in previous studies [18-20]. We used the dominant model for GSTM1 and GSTT1 and the recessive model for $A L D H 2$ and PONI in the test analysis.

\section{Ethical considerations}

The Ethics Review Board of Miyazaki University (no. 82, April 9, 2003) and Kumamoto University (no. 168, May 11 , 2011) approved this study, following the ethical guidelines for human genome research. All participants were given full explanations of informed consent and the full protection of their personal data in written form.

\section{Results}

Table 1 presents the frequency of MCS, sick house syndrome, and allergic diseases such as asthma, allergic coryza, and atopic dermatitis. Four subjects reported history of diagnosis of MCS, three of whom also had history of allergy. The QEESI score and genotypes of these 4 subjects were as follows: (1) Q1 (27), Q2 (15), Q3 (36), GSTM1 null, GSTT1 null, ALDH2*I/*1 and PON1 Arg/Arg; (2) Q1 (38), Q2 (5), Q3 (14), GSTM1 null, GSTT1 null, ALDH2*1/*1 and PON1 Arg/Arg; (3) Q1 (27), Q2 (30), Q3 (78), GSTM1 non-null, GSTT1 non-null, ALDH2*1/*1 and PON1 Arg/Arg; and (4) Q1 (9), Q2 (12), Q3 (23), GSTM1 non-null, GSTT1 null, ALDH2*1/*2 and PON1 Arg/Arg. No subjects in this study population had diagnosis of sick house syndrome.

Chemical sensitivity was estimated by high cutoff values in the three subscales of chemical sensitivity $(\geq 40)$, other chemical sensitivity ( $\geq 25)$, and symptom severity $(\geq 40)$. The percentage of subjects to whom high cutoff values were applied for the subscales of chemical sensitivity, other chemical sensitivity, and symptom severity were $7.1 \%$, $3.1 \%$, and $6.8 \%$, respectively. The risks for chemical sensitivity as defined by Miller and Prihoda, estimated by high cutoff values on two subscales or three subscales, were $2.9 \%$ $(n=31)$ and $0.7 \%(n=8)$, respectively.

When Hojo et al. [17] confirmed that the QEESI is effective for screening Japanese MCS patients, they suggested that the cutoff values for Japanese subjects should be chemical sensitivity score $\geq 40$ and symptom severity score $\geq 20$. In our study population, $4.3 \%(n=47)$ of the subjects met that criteria and were defined as the cases (Table 2). There was a significant difference between the cases and controls in smoking status. However, no significant differences between the two groups in drinking status were observed.

Next we examined the association between genetic variants in GSTM1, GSTT1, ALDH2, and PON1 and chemical sensitivity in the total population and the casecontrol population. The frequencies of genotypes for all examined gene variants by chemical sensitivity subscale score are presented in Table 3. On the chemical sensitivity subscale, $32.7 \%$ scored $0,42.7 \%$ scored from 1 to 19 , $17.5 \%$ scored from 20 to 39 , and $7.1 \%$ scored 40 or higher. On the other chemical sensitivity subscale, $26.6 \%$ scored 0 , $67.9 \%$ scored from 1 to $19,5.0 \%$ scored from 20 to 39 , and $0.5 \%$ scored 40 or higher (Electronic Supplementary Table S1). On the symptom severity subscale, $15.5 \%$ scored $0,54.9 \%$ scored from 1 to $19,22.8 \%$ scored from 20 to 39 , and $6.8 \%$ scored 40 or higher (Electronic Supplementary Table S2). No significant difference in frequency was found for any gene variant between any levels in the total population or on any subscale of the QEESI. Similarly, there were no significant differences between the QEESI scores of genetic variants in GSTM1, GSTT1, $A L D H 2$, and PON1 (Table 3, Electronic Supplementary Tables S1 and S2).

The genotype data were also analyzed in the casecontrol design using logistic regression analyses with chemical sensitive status (cases: chemical sensitivity score $\geq 40$ and symptom severity score $\geq 20$ ) as outcome variables and genotype as the predictor variable, as presented in Table 4. No categorical predictor variable reached statistical significance. To check the effect of the genes in combination with smoking status, we calculated the OR for data classified by smoking status and by gene genotypes. The summarized data and ORs are presented in Table 5 together with $95 \%$ CIs. None of the distributions of genotypes showed any significant differences from the controls.

\section{Discussion}

This study focused on gene polymorphisms as a factor of chemical sensitivity, and analyzed GSTM1, GSTT1, $A L D H 2$, and PON1.

Schnakenberg et al. [21] observed that the GSTM1 and GSTT1 gene deletion genotype occurred significantly more often in those individuals in German populations who reported chemical-related hypersensitivity. On the other hand, the allele and genotype frequencies of GSTM1 and GSTT1 were similar in Italian MCS patients and control populations [22]. In our study, no significant differences between the genotype frequency of GSTT1 and GSTM1 were found for any severity of three QEESI subscales or in the case-control study. The contradictory results are 
Table 3 Association of QEESI chemical sensitivity subscale score with variants of GSTM1, GSTT1, ALDH2, and PON1

\begin{tabular}{|c|c|c|c|c|c|c|c|}
\hline \multirow[t]{2}{*}{ Gene } & \multirow[t]{2}{*}{ Genotype } & \multicolumn{6}{|c|}{ QEESI score } \\
\hline & & $\begin{array}{l}0 \\
n(\%) \\
354(32.7)\end{array}$ & $\begin{array}{l}1-19 \\
n(\%) \\
463(42.7)\end{array}$ & $\begin{array}{l}20-39 \\
n(\%) \\
190(17.5)\end{array}$ & $\begin{array}{l}40-100 \\
n(\%) \\
77(7.1)\end{array}$ & $\begin{array}{l}\text { Total } \\
n(\%) \\
1,084(100)\end{array}$ & $P$ value $^{\mathrm{a}}$ \\
\hline \multirow[t]{2}{*}{ GSTM1 } & Non-null & $152(42.9)$ & $213(46.0)$ & $95(50.0)$ & $36(46.8)$ & $496(45.8)$ & \\
\hline & Homozygous-null & $202(57.1)$ & $250(54.0)$ & $95(50.0)$ & $41(53.2)$ & $588(54.2)$ & 0.47 \\
\hline \multirow[t]{2}{*}{ GSTT1 } & Non-null & $199(56.2)$ & $257(55.5)$ & $99(52.1)$ & $48(62.3)$ & $603(55.6)$ & \\
\hline & Homozygous-null & $155(43.8)$ & $206(44.5)$ & $91(47.9)$ & $29(37.7)$ & $481(44.4)$ & 0.49 \\
\hline \multirow[t]{4}{*}{$A L D H 2$} & $* 1 / * 1$ & $222(62.7)$ & $276(59.6)$ & $113(59.5)$ & $54(70.1)$ & $665(61.3)$ & \\
\hline & $* 1 / * 2$ & $109(30.8)$ & $166(35.9)$ & $66(34.7)$ & $20(26.0)$ & $361(33.3)$ & \\
\hline & $* 2 / * 2$ & $23(6.5)$ & $21(4.5)$ & $11(5.8)$ & $3(3.9)$ & $58(5.4)$ & \\
\hline & $* 1 / * 2$ or $* 2 / * 2$ & $131(37.3)$ & $187(40.4)$ & $77(40.5)$ & $23(29.9)$ & 419 (38.7) & $0.30^{\mathrm{b}}$ \\
\hline \multirow[t]{4}{*}{ PON1 } & Arg/Arg & $147(41.5)$ & $178(38.5)$ & $81(42.6)$ & $33(42.8)$ & $439(40.5)$ & \\
\hline & Arg/Gln & $185(52.3)$ & $253(54.6)$ & $91(47.9)$ & $38(49.4)$ & $567(52.3)$ & \\
\hline & $G \ln / G \ln$ & $22(6.2)$ & $32(6.9)$ & $18(9.5)$ & $6(7.8)$ & $78(7.2)$ & \\
\hline & $A r g / G \ln$ or $G l n / G l n$ & $207(58.5)$ & $285(61.5)$ & $109(57.4)$ & $44(57.2)$ & $645(59.5)$ & $0.68^{\mathrm{c}}$ \\
\hline
\end{tabular}

${ }^{a} P$ value, chi-square test. $P<0.05$, difference significant

b $* 1 / * 2$ or $* 2 / * 2$ against $* 1 / * 1$

c Arg/Gln or Gln/Gln against Arg/Arg

Table 4 Association of cases and controls defined by QEESI score with the variants of GSTM1, GSTT1, ALDH2, and PON1

\begin{tabular}{|c|c|c|c|c|c|c|}
\hline Gene & Genotype & $\begin{array}{l}\text { Cases (CSP) } \\
n=47(\%)\end{array}$ & $\begin{array}{l}\text { Controls } \\
n=1037(\%)\end{array}$ & Crude $\mathrm{OR}^{\mathrm{a}}$ & $P$ value $^{\mathrm{b}}$ & Adjusted $\mathrm{OR}^{\mathrm{b}, \mathrm{c}}$ \\
\hline \multirow[t]{2}{*}{ GSTM1 } & Non-null & $20(42.6)$ & $476(45.9)$ & 1 & & 1 \\
\hline & Homozygous-null & $27(57.4)$ & $561(54.1)$ & $1.15(0.61-2.15)$ & 0.62 & $1.16(0.64-2.10)$ \\
\hline \multirow[t]{2}{*}{ GSTT1 } & Non-null & $31(66.0)$ & $572(55.2)$ & 1 & & 1 \\
\hline & Homozygous-null & $16(34.0)$ & $465(44.8)$ & $0.63(0.33-1.22)$ & 0.12 & $0.61(0.33-1.13)$ \\
\hline \multirow[t]{4}{*}{$A L D H 2$} & $* 1 / * 1$ & $32(68.1)$ & $633(61.0)$ & 1 & & 1 \\
\hline & $* 1 / * 2$ & $13(27.7)$ & $348(33.6)$ & & & \\
\hline & $* 2 / * 2$ & $2(4.2)$ & $56(5.4)$ & & & \\
\hline & $* 1 / * 2$ or $* 2 / * 2$ & $15(31.9)$ & $404(39.0)$ & $0.73(0.37-1.42)$ & $0.18^{\mathrm{d}}$ & $0.63(0.32-1.24)^{\mathrm{d}}$ \\
\hline \multirow[t]{4}{*}{ PON1 } & Arg/Arg & $19(40.4)$ & $420(40.5)$ & 1 & & 1 \\
\hline & Arg/Gln & $25(53.2)$ & $542(52.3)$ & & & \\
\hline & $G \ln / G \ln$ & $3(6.4)$ & $75(7.2)$ & & & \\
\hline & $A r g / G \ln$ or $G \ln / G \ln$ & $28(59.6)$ & $617(59.5)$ & $1.00(0.53-1.88)$ & $0.85^{\mathrm{e}}$ & $1.06(0.58-1.94)^{\mathrm{e}}$ \\
\hline
\end{tabular}

${ }^{a}$ Odds ratio (OR) and 95\% confidence interval (95\% CI)

b $P$ value, chi-square test. $P<0.05$, difference significant

c ORs were adjusted for age (continuous), gender, smoking, and drinking

d $* 1 / * 2$ or $* 2 / * 2$ against $* 1 / * 1$

e $A r g / G l n$ or $G l n / G l n$ against $A r g / A r g$

mainly due to the inclusion criteria adopted by the different studies.

Our study is the first to analyze the association between $A L D H 2$ variants and chemical sensitivity, and no significant association was observed in our Japanese population. This result suggests that the $A L D H 2$ variants may not be involved in CSP.
PON1 plays a major role in biodegradation of various organophosphates that can function as potent cholinesterase inhibitors. Previous studies suggested that the polymorphic site in PONI was related to an increased risk of MCS [23] and Gulf War Syndrome, which is an MCSrelated syndrome [15]. However, no significant association between the Gln192Arg polymorphism and PON1 was 
Table 5 Odds ratio for genotypes related to CSP by smoking status

\begin{tabular}{|c|c|c|c|}
\hline Gene & Genotype & $\begin{array}{l}\text { Nonsmokers, } \\
\text { OR }(95 \% \mathrm{CI})^{\mathrm{a}} \\
n=481 \\
(44.6 \%)\end{array}$ & $\begin{array}{l}\text { Smokers } \\
\text { (>once/week), } \\
\text { OR }(95 \% \mathrm{CI})^{\mathrm{a}} \\
n=603 \\
(55.6 \%)\end{array}$ \\
\hline GSTM1 & $\begin{array}{l}\text { Homozygous-null } \\
\text { versus non-null } \\
\text { genotype }\end{array}$ & $1.49(0.69-3.23)$ & $0.78(0.30-2.01)$ \\
\hline GSTT1 & $\begin{array}{l}\text { Homozygous-null } \\
\text { versus non-null } \\
\text { genotype }\end{array}$ & $1.18(0.36-3.92)$ & $0.85(0.32-2.23)$ \\
\hline$A L D H 2$ & $\begin{array}{c}* 1 / * 2 \text { or } * 2 / * 2 \\
\text { versus } * 1 / * 1\end{array}$ & $1.21(0.37-4.00)$ & $0.50(0.15-1.67)$ \\
\hline PON1 & $\begin{array}{c}A r g / G l n \text { or } G l n / G l n \\
\text { versus } A r g / A r g\end{array}$ & $1.24(0.38-4.09)$ & $1.08(0.41-2.85)$ \\
\hline
\end{tabular}

${ }^{a}$ ORs were adjusted for age (continuous), gender, and drinking

obtained in our study. This trend in the MCS case-control design was reversed in the general population samples, perhaps reflecting that the PON1 polymorphism played a minor or no role in the development of MCS in our population. In support of our study, Wiesmuller et al. [24] failed to detect an association between PON1 polymorphism and self-reported MCS in a population sample.

On the other hand, we tried to define chemical sensitivity cases by Miller and Prihoda and estimated the risk for the genetic variants of GSTM1, GSTT1, ALDH2, and $P O N 1$, respectively. However, no case-control differences were observed in each genotype of the 4 genes.

Smoking status was significantly lower in the cases than in the controls. Several reports suggest that MCS patients who are aware of their chemical intolerance avoid exogenous chemicals such as those from smoking [23, 24]. Tobacco smoke contains many kinds of chemicals, including formaldehyde and acetaldehyde [25]. For these reasons, we hypothesize that the genotypes of GSTM1, GSTT1, ALDH2, and PON1 might contribute to development of CSP in smokers. However, among the smokers there were no significant differences between CSP and controls in the GSTM1, GSTT1, $A L D H 2$, and $P O N 1$ genotypes.

In the present study, no significant differences between sequence variations of GSTM1, GSTT1, ALDH2, and PON1 were found between the CSPs and controls. One possible weakness of our study design is a lack of assessments of environmental exposure to chemicals metabolized by the examined enzymes. It is plausible that gene-environment interactions exist, and the genetic variations of metabolic enzymes may either confer protection against or increase risk from harmful effects of chemical exposure. A second problem is the possibility that the subject sample we defined, following the QEESI protocols, was not a correct sampling of MCS. Our survey included the other chemical sensitivity subscale, but not life impact. Extrapolating from the results of Hojo et al., our defined cases whose scores exceeded the two cutoff values of chemical sensitivity $\geq 40$ and symptom severity $\geq 20$ were considered to be equivalent to $65 \%$ of the patients suspected to have MCS and $7 \%$ of the healthy controls. This screening criteria means that detecting the condition has sensitivity of $65 \%$ and specificity of $93 \%$. It is unlikely that sensitivity, specificity, positive predictive value, and negative predictive value are influenced by the prevalence of the disease. As a result of that, we might not have been able to find the effect of important genotypes. A future strategy could be to subgroup patients according to symptoms, which may be genetically more homogeneous that a patient population as whole.

In conclusion, an association between risks for CSPrelated MCS and genetic variation in biologically plausible candidate genes was not observed. Additionally, our results suggest that an exact case criterion is required to determine the actual importance to MCS of genetic variants in genes that encode metabolic enzymes.

Acknowledgments We are most grateful to Dr. Hiroyuki Nakao in the Department of Health Policy and Technology Assessment, National Institute of Public Health, for his technical advice in the statistical analysis. We express our sincere appreciation to the staff members of the Department of Public Health and the Department of Preventive and Environmental Medicine, Faculty of Life Sciences, Kumamoto University. This work was supported in part by Grants-inAid for Research on Health Security Control from the Ministry of Health, Labor, and Welfare of Japan (H23-Kenki-Ipan).

Conflict of interest No conflicts of interest.

\section{References}

1. American Academy of Allergy, Asthma, and Immunology. Idiopathic environmental intolerances. J Allergy Clin Immunol. 1999;103:36-40.

2. Winder C. Mechanisms of multiple chemical sensitivity. Toxicol Lett. 2002;128:85-97.

3. Cullen MR. The worker with multiple chemical sensitivities: an overview. Occup Med. 1987;2:655-61.

4. Labarge AS, McCaffrey RJ. Multiple chemical sensitivity: a review of the theoretical and research literature. Neuropsychol Rev. 2000;10:183-211.

5. Miller CS, Prihoda TJ. The Environmental Exposure and Sensitivity Inventory (EESI): a standardized approach for measuring chemical intolerances for research and clinical applications. Toxicol Ind Health. 1999;15:370-85.

6. Miller CS, Prihoda TJ. A controlled comparison of symptoms and chemical intolerances reported by Gulf War veterans, implant recipients and persons with multiple chemical sensitivity. Toxicol Ind Health. 1999;15:386-97.

7. Ashford NA, Miller CS. Appendix C: environmental exposure and sensitivity inventory. In: Chemical exposures: low levels and high stakes. 2nd ed. New York: Wiley; 1998. p. 371-84. 
8. Ishikawa S, Miyata M. Multiple chemical sensitivity-criteria and test methods for diagnosis. Allergol Immunol. 1999;6:990-8.

9. Hayes JD, Pulford DJ. The glutathione $S$-transferase supergene family: regulation of GST and the contribution of the isoenzymes to cancer chemoprotection and drug resistance. Crit Rev Biochem Mol Biol. 1995;30:445-600.

10. Pemble S, Schroeder KR, Spencer SR, Meyer DJ, Hallier E, Bolt $H M$, et al. Human glutathione $S$-transferase Theta (GSTT1): cDNA cloning and the characterization of a genetic polymorphism. Biochem J. 1994;300:271-6.

11. Ben-Arie N, Khen M, Lancet D. Glutathione $S$-transferases in rat olfactory epithelium: purification, molecular properties and odorant biotransformation. Biochem J. 1993;292:379-84.

12. Saito M, Kumano H, Yoshiuchi K, Kokubo N, Ohashi K, Yamamoto $\mathrm{Y}$, et al. Symptom profile of chemical sensitivity in actual life. Psychosom Med. 2005;67:318-25.

13. Harada S, Zhang S. New strategy for detection of ALDH2 mutant. Alcohol Alcohol Suppl. 1993;1A:11-3.

14. Smolen A, Eckerson HW, Gan KN, Hailat N, La Du BN. Characteristics of the genetically determined allozymic forms of human serum paraoxonase/arylesterase. Drug Metab Dispos. 1991;19:107-12.

15. Haley RW, Billecke S, La Du BN. Association of low PON1 type $\mathrm{Q}$ (type A) arylesterase activity with neurologic symptom complexes in Gulf War veterans. Toxicol Appl Pharmacol. 1999;157: 227-33.

16. La Du BN, Aviram M, Billecke S, Navab M, Primo-Parmo S, Sorenson RC, et al. On the physiological role(s) of the paraoxonases. Chem Biol Interact. 1999;119-120:379-88.

17. Hojo S, Sakabe K, Ishikawa S, Miyata M, Kumano H. Evaluation of subjective symptoms of Japanese patients with multiple chemical sensitivity using QEESI((c)). Environ Health Prev Med. 2009;14:267-75.
18. Katoh T, Nagata N, Kuroda Y, Itoh H, Kawahara A, Kuroki N, et al. Glutathione $S$-transferase M1 (GSTM1) and T1 (GSTT1) genetic polymorphism and susceptibility to gastric and colorectal adenocarcinoma. Carcinogenesis. 1996;17:1855-9.

19. Yamasaki Y, Sakamoto K, Watada H, Kajimoto Y, Hori M. The Arg192 isoform of paraoxonase with low sarin-hydrolyzing activity is dominant in the Japanese. Hum Genet. 1997;101:67-8.

20. Takeshita T, Morimoto K, Mao X, Hashimoto T, Furuyama J. Characterization of the three genotypes of low $\mathrm{Km}$ aldehyde dehydrogenase in a Japanese population. Hum Genet. 1994;94: 217-23.

21. Schnakenberg E, Fabig KR, Stanulla M, Strobl N, Lustig M, Fabig N, et al. A cross-sectional study of self-reported chemicalrelated sensitivity is associated with gene variants of drugmetabolizing enzymes. Environ Health. 2007;6:6.

22. De Luca C, Scordo MG, Cesareo E, Pastore S, Mariani S, Maiani $\mathrm{G}$, et al. Biological definition of multiple chemical sensitivity from redox state and cytokine profiling and not from polymorphisms of xenobiotic-metabolizing enzymes. Toxicol Appl Pharmacol. 2010;248:285-92.

23. McKeown-Eyssen G, Baines C, Cole DE, Riley N, Tyndale RF, Marshall L, et al. Case-control study of genotypes in multiple chemical sensitivity: CYP2D6, NAT1, NAT2, PON1, PON2 and MTHFR. Int J Epidemiol. 2004;33:971-8.

24. Wiesmüller GA, Niggemann H, Weissbach W, Riley F, Maarouf $\mathrm{Z}$, Dott $\mathrm{W}$, et al. Sequence variations in subjects with selfreported multiple chemical sensitivity (sMCS): a case-control study. J Toxicol Environ Health A. 2008;71:786-94.

25. Pang X, Lewis AC. Carbonyl compounds in gas and particle phases of mainstream cigarette smoke. Sci Total Environ. 2011;409:5000-9. 